\title{
Increased Prescribing of Psychotropic Medications to Ontario Nursing Home Residents during the COVID-19 Pandemic
}

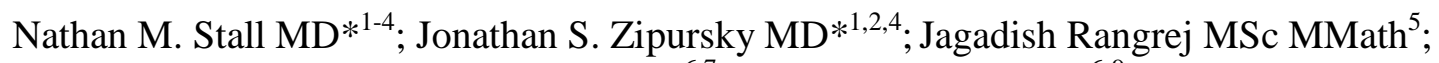 \\ Aaron Jones MSc, $\mathrm{PhD}^{6,7}$; Andrew P. Costa $\mathrm{PhD}^{6-9}$; \\ Michael P. Hillmer MSc, $\mathrm{PhD}^{4,5}$; Kevin Brown MSc, PhD ${ }^{10,11}$
}

\author{
*Co-first authors \\ ${ }^{1}$ Division of General Internal Medicine and Geriatrics, Sinai Health System and the University Health Network, \\ Toronto, Canada \\ ${ }^{2}$ Department of Medicine, University of Toronto, Toronto, Canada \\ ${ }^{3}$ Women's College Research Institute, Women's College Hospital, Toronto, Canada \\ ${ }^{4}$ Institute of Health Policy, Management and Evaluation, University of Toronto, Toronto, Canada \\ ${ }^{5}$ Capacity Planning and Analytics, Ontario Ministry of Health, Toronto, \\ ${ }^{6}$ Department of Health Research Methods, Evidence, and Impact, McMaster University, Hamilton, Canada \\ ${ }^{7}$ ICES, Toronto, Canada \\ ${ }^{8}$ Schlegel Chair in Clinical Epidemiology and Aging, McMaster University, Hamilton, Ontario, Canada \\ ${ }^{9}$ Centre for Integrated Care, St. Joseph's Health System, Hamilton, Ontario, Canada \\ ${ }^{10}$ Infection Prevention and Control, Public Health Ontario, Toronto, Canada \\ ${ }^{11}$ Dalla Lana School of Public Health, University of Toronto, Toronto, Canada
}

\author{
Corresponding author: Nathan M. Stall MD, FRCPC \\ Division of Geriatric Medicine, Department of Medicine \\ Institute of Health Policy, Management \& Evaluation \\ University of Toronto \\ Mount Sinai Hospital \\ Suite 475 - 600 University Ave. \\ Toronto, Ontario M5G 1X5 Canada \\ Phone: 416-351-3732 x2711 \\ Email: nathan.stall@ sinaihealth.ca
}

Word count: 670

Figures: 1

Tables: 1

References: 6

\begin{abstract}
In this population-based study of all Ontario nursing home residents, we found increased prescribing of psychotropic drugs at the onset of the COVID-19 pandemic that persisted through September 2020. Increases in prescribing were out of proportion to expected secular trends, and distinct from observed prescribing changes in other drugs during the pandemic. Our findings underscore the urgency of balancing infection prevention and control measures in nursing homes with the mental wellbeing of residents.
\end{abstract}




\section{Introduction}

An enduring feature of the COVID-19 pandemic is the sizeable number of outbreaks and deaths in nursing homes. To limit the introduction of virus in these settings, strict and lengthy lockdowns were imposed on nursing homes worldwide. These restrictions have led to concerns about the mental health of nursing home residents, and increases in the use of psychotropic medications, which were frequently overprescribed prior to the pandemic. ${ }^{1,2}$

\section{Methods}

We examined the monthly proportion of nursing home residents in Canada's most populous province of Ontario dispensed psychotropics from January-September 2020. As of March 1, 2020, there were 77,291 residents living in the province's 623 licensed nursing homes receiving personal and nursing care, subsidized accommodation and all prescription medications under a publicly long-term care program. Restrictions on visitation, absences, and most congregate dining and group activities began in all nursing homes on March 14, 2020.

We studied the dispensation of four psychotropic medications: antipsychotics $\left(1^{\text {st }}\right.$-and- $2^{\text {nd }}$ generation), antidepressants (SSRIs, SNRIs, bupropion, mirtazapine), benzodiazepines, and trazodone. We also examined the prescribing of two negative tracer drugs (metformin and statins) not expected to change during the pandemic. Data were obtained from the Ontario Drug Benefit database through the Ministry of Health as part of the province's COVID-19 Modeling Consensus Table.

We examined the proportion of residents receiving a prescription across the first seven months of the pandemic (March-September 2020). To account for the dynamic number of residents living in nursing homes during the pandemic, we calculated the monthly number of residents filling a prescription for each drug of interest as a proportion of the monthly number of residents filling a prescription for any drug. In unadjusted analyses, we examined absolute changes in the proportion of residents receiving a prescription compared to the most recent pre-pandemic months (January-February 2020). In adjusted analyses, we examined absolute changes compared to anticipated absolute prescribing trends based on the linear secular trend of prescribing rates 
from April 2019 to February 2020. All analyses were based on logistic regression. The study was approved by the University of Toronto's research ethics board.

\section{Results}

Comparing January-February 2020 with September 2020 (Table 1), there were absolute increases in the proportion of nursing home residents who received prescriptions for antipsychotics (1.6\%, 95\% Confidence Internal (CI): 0.9-2.4), antidepressants (1.6\%, 95\%CI: 1.0-2.2), and trazodone (1.0\%, 95\%CI: 0.3-1.8). While benzodiazepine prescribing decreased slightly $(-0.2 \%, 95 \% \mathrm{CI}$ : 1.0-0.6), the adjusted analysis (Figure 1) revealed an increase relative to apparent negative secular trends $(0.3 \%, 95 \% \mathrm{CI}$ : -0.3-0.9). Deviations above positive secular trends were also present in adjusted analyses for all other psychotropics, including antipsychotics $(1.7 \%, 95 \% \mathrm{CI}$ : 1.1-2.2), antidepressants (1.4\%, 95\%CI: 0.9-1.8), and trazodone (1.1\%, 95\%CI: 0.6-1.7). Comparatively, there were decreases in the proportion of residents prescribed metformin $(-0.3 \%$, 95\%CI: $-1.1-0.5)$ and statins (-0.7\%, 95\%CI: $-1.4-0.1)$, and these decreases were more pronounced after adjustment for secular trends (-0.6\%, 95\%CI:-1.2-0.0 and -1.4\%, 95\%CI: -1.9-0.8 , respectively).

\section{Discussion}

In this population-based study of all Ontario nursing home residents, we found increased prescribing of psychotropic drugs at the onset of the COVID-19 pandemic that persisted through September 2020. Increases in prescribing were out of proportion to expected secular trends, and distinct from observed prescribing changes in other drugs during the pandemic.

Our results align with findings of increased prescribing of antipsychotics during the pandemic to people living with dementia in the United Kingdom. ${ }^{3}$ We offer additional insights by studying prescribing of multiple classes of psychotropic drugs, as well as those unexpected to change during the pandemic. Our study is limited by lack of data on prescribing indications; while some of the observed increases in psychotropics may be for palliative management of residents dying of COVID-19, increases were more likely related to the effects of prolonged social isolation during lockdowns. ${ }^{4,5}$ Due to diminished resources, clinicians may have been less likely to prioritize more favorable non-pharmacological management for common issues like responsive 
medRxiv preprint doi: https://doi.org/10.1101/2020.11.26.20239525; this version posted November 30, 2020. The copyright holder for this preprint (which was not certified by peer review) is the author/funder, who has granted medRxiv a license to display the preprint in perpetuity.

It is made available under a CC-BY-NC-ND 4.0 International license .

behaviours. Overall, our findings underscore the urgency of balancing infection prevention and control measures in nursing homes with the mental wellbeing of residents. ${ }^{6}$

Financial Support: This study was not funded. Dr. Stall is supported by the University of

Toronto Department of Medicine's Eliot Phillipson Clinician-Scientist Training Program and the Vanier Canada Graduate Scholarship.

Disclosures: The authors have no conflicts of interest to disclose.

\section{References}

1. Abbasi J. Social Isolation-the Other COVID-19 Threat in Nursing Homes. JAMA. 2020.

2. Rochon PA, Stukel TA, Bronskill SE, et al. Variation in nursing home antipsychotic prescribing rates. Arch Intern Med. 2007;167(7):676-683.

3. Howard R, Burns A, Schneider L. Antipsychotic prescribing to people with dementia during COVID-19. Lancet Neurol. 2020;19(11):892.

4. Van der Roest HG, Prins M, van der Velden C, et al. The impact of COVID-19 measures on well-being of older long-term care facility residents in the Netherlands. Journal of the American Medical Directors Association. 2020.

5. Cagnin A, Di Lorenzo R, Marra C, et al. Behavioral and Psychological Effects of Coronavirus Disease-19 Quarantine in Patients With Dementia. Front Psychiatry. 2020;11:578015.

6. Bergman C, Stall NM, Haimowitz D, et al. Recommendations for Welcoming Back Nursing Home Visitors during the COVID-19 Pandemic: Results of a Delphi Panel. Journal of the American Medical Directors Association. 2020. 
medRxiv preprint doi: https://doi.org/10.1101/2020.11.26.20239525; this version posted November 30, 2020. The copyright holder for this preprint (which was not certified by peer review) is the author/funder, who has granted medRxiv a license to display the preprint in perpetuity.

It is made available under a CC-BY-NC-ND 4.0 International license .

Figure 1: Changes in psychotropic drug prescribing to nursing home residents in Ontario, Canada (April 2019 through September 2020)

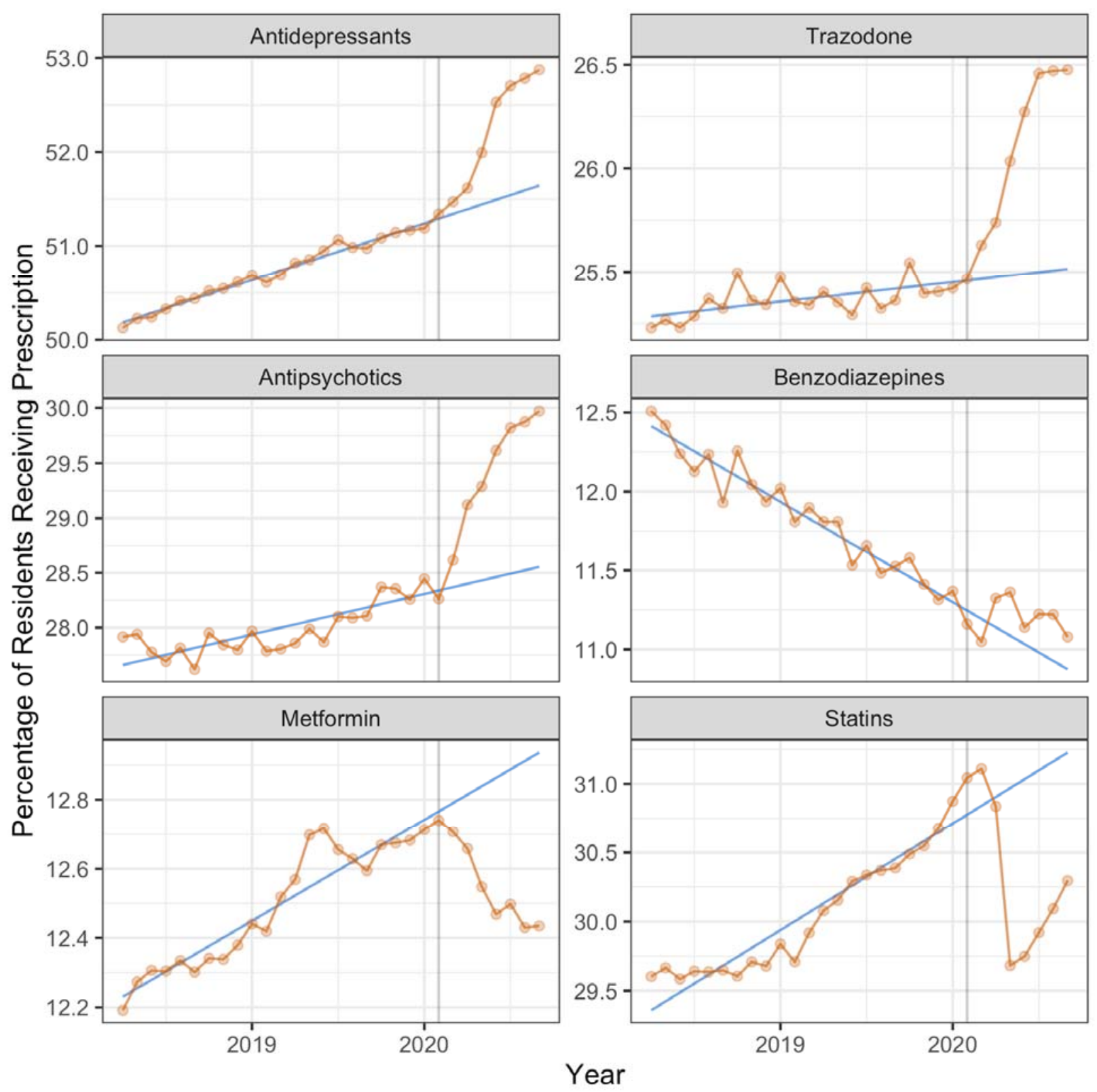

Figure 1: Monthly proportion of residents filling a prescription for each drug class from April 2019 to September 2020. As of March 1, 2020, there were 77,291 residents living in Ontario's 623 licensed nursing homes. The grey vertical line represents the onset of the COVID-19 lockdown in Ontario (March 2020). The blue line represents expected prescribing based on secular trends prior to the lockdown. 
Table 1: Unadjusted and adjusted absolute changes in psychotropic drug prescribing to nursing home residents in Ontario, Canada (January-September, 2020)

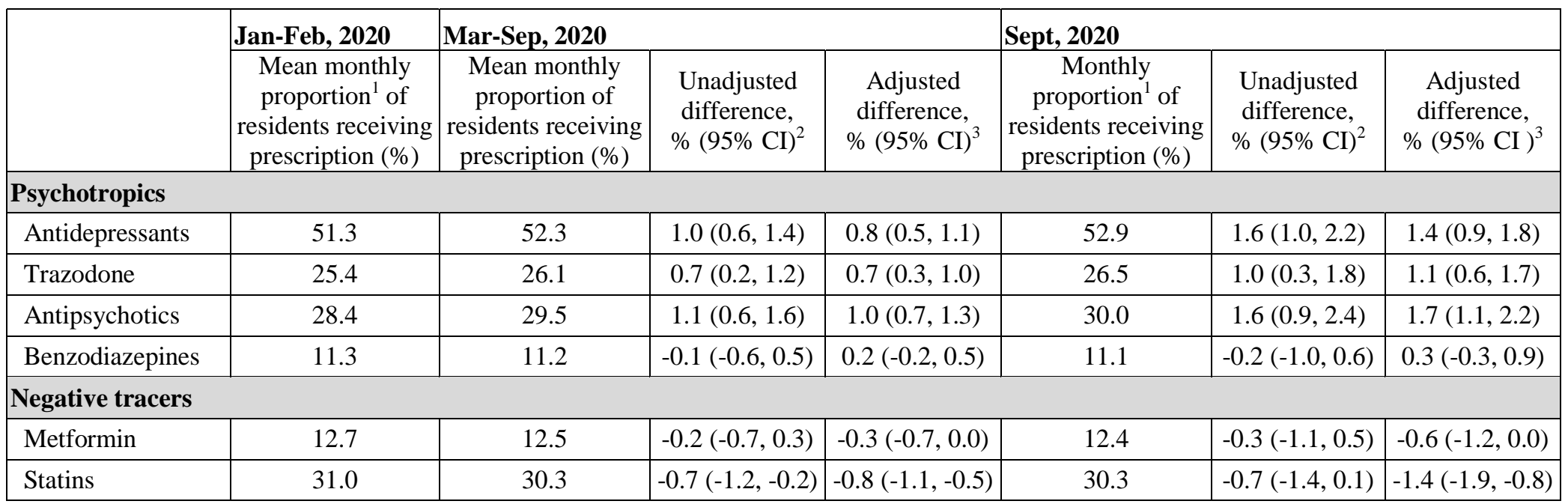

${ }^{1}$ The monthly number of residents filling a prescription of interest as a proportion of the monthly number of residents filling a prescription for any drug. As of March 1, 2020 there were 77,291 residents living in Ontario's 623 licensed nursing homes.

${ }^{2}$ Unadjusted absolute difference with 95\% Confidence Interval (CI) compared to January-February, 2020.

${ }^{3}$ Adjusted absolute difference with $95 \%$ Confidence Interval (CI) compared to prescribing rates expected based on a linear secular trend in the April 2019 to February 2020 period. 